\title{
Discriminating between Different Heavy Metal Ions with Fullerene-Derived Nanoparticles
}

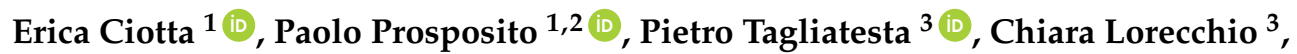

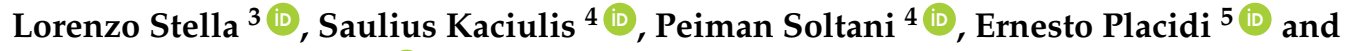 \\ Roberto Pizzoferrato ${ }^{1, *}$ (iD \\ 1 Department of Industrial Engineering, University of Rome Tor Vergata, 00133 Rome, Italy; \\ Erica.Ciotta@uniroma2.it (E.C.); paolo.prosposito@uniroma2.it (P.P.) \\ 2 INSTM and CiMER, University of Rome Tor Vergata, 00133 Rome, Italy \\ 3 Department of Chemical Sciences and Technology, University of Rome Tor Vergata, 00133 Rome, Italy; \\ pietro.tagliatesta@uniroma2.it (P.T.); chiaralorec@hotmail.it (C.L.); stella@stc.uniroma2.it (L.S.) \\ 4 Institute for the Study of Nanostructured Materials, CNR of Italy, Monterotondo Stazione, 00015 Rome, Italy; \\ saulius.kaciulis@ismn.cnr.it (S.K.); peymansoltani14@gmail.com (P.S.) \\ 5 CNR-Istituto di Struttura della Materia, Via Fosso del Cavaliere 100, 00133 Roma, Italy; \\ ernesto.placidi@roma2.infn.it \\ * Correspondence: pizzoferrato@uniroma2.it; Tel.: +39-06-7259-7192; Fax: +39-06-2021-351
}

Received: 9 April 2018; Accepted: 8 May 2018; Published: 10 May 2018

\begin{abstract}
A novel type of graphene-like nanoparticle, synthesized by oxidation and unfolding of $\mathrm{C}_{60}$ buckminsterfullerene fullerene, showed multiple and reproducible sensitivity to $\mathrm{Cu}^{2+}, \mathrm{Pb}^{2+}$, $\mathrm{Cd}^{2+}$, and As(III) through different degrees of fluorescence quenching or, in the case of $\mathrm{Cd}^{2+}$, through a remarkable fluorescence enhancement. Most importantly, only for $\mathrm{Cu}^{2+}$ and $\mathrm{Pb}^{2+}$, the fluorescence intensity variations came with distinct modifications of the optical absorption spectrum. Time-resolved fluorescence study confirmed that the common origin of these diverse behaviors lies in complexation of the metal ions by fullerene-derived carbon layers, even though further studies are required for a complete explanation of the involved processes. Nonetheless, the different response of fluorescence and optical absorbance towards distinct cationic species makes it possible to discriminate between the presence of $\mathrm{Cu}^{2+}, \mathrm{Pb}^{2+}, \mathrm{Cd}^{2+}$, and $\mathrm{As}(\mathrm{III})$, through two simple optical measurements. To this end, the use of a three-dimensional calibration plot is discussed. This property makes fullerene-derived nanoparticles a promising material in view of the implementation of a selective, colorimetric/fluorescent detection system.
\end{abstract}

Keywords: optical sensors; heavy metals; carbon nanoparticles; metal complexation; fluorescence quenching; fluorescence turn-on

\section{Introduction}

Research on nanostructured materials has recently produced noteworthy results in several fields, including biology, medicine, energy, and sensors [1-6]. In particular, graphene nanoparticles, also referred to as graphene oxide quantum dots (GOQDs), have demonstrated themselves to be a fluorescent nanomaterial with possible applications in chemical and biological optical sensing [7-11]. In fact, the stable blue/green fluorescent emission reported by several groups in GOQDs [12-16], regardless of the different synthesis methods, exhibited a fluorescence-quenching effect in the presence of certain heavy metal ions $\left(\mathrm{Hg}^{2+}, \mathrm{Fe}^{3+}, \mathrm{Cu}^{2+}, \mathrm{Pb}^{2+}\right)$, generally attributed to the metal ion chelating with the different functional groups [17-24]. This property makes GOQDs promising for applications in optical sensors for the detection of heavy metals, which have long been known as highly toxic for 
human health above certain concentration values $[25,26]$. In the Guidelines for Drinking-Water Quality by World Health Organization (WHO) [27], for instance, the limit for arsenic and lead is $10 \mu \mathrm{g} / \mathrm{L}$, for cadmium is $3 \mu \mathrm{g} / \mathrm{L}$, while for copper it reaches up to $2 \mathrm{mg} / \mathrm{L}$. In order to detect and measure heavy metal concentrations, potentially portable, fast, easy-to-use, and cheap optical methods are desirable, since the traditional techniques for standard laboratory analysis generally need expensive and heavy instrumentation which require highly skilled staff and time consuming procedures [28]. To this end, compared to other fluorometric materials, GOQDs seem to offer some distinct advantages that could offset a generally lower sensitivity [17]. In comparison to molecular fluorophores, for instance, GOQDs possess higher stability with respect to photobleaching and better biocompatibility, as it was demonstrated in several studies on bioimaging, with specific regard to live cell labelling and imaging [7-11,29,30]. Moreover, sensing properties have also been found in bare GOQDs, i.e., without a specific metal-oriented functionalization, differently from semiconductor quantum dots and metal nanoparticles, which need capping agents, and are therefore quite affected by the nature of surface states $[3,31]$. In fact, the intrinsic presence of oxygen-containing functional groups gives GOQDs a hydrophilic character that naturally stabilizes nanoparticle suspensions in aqueous media without any further functionalization [17]. However, few experimental studies have been performed, so far, in bare GOQDs, to assess the chance of practical applications of the sensing effect. In addition, the analysis of the literature shows variable and contradictory results, which also depend on the synthesis procedures. For instance, fluorescence quenching in the presence of $\mathrm{Fe}^{3+}$ ions was found by Wang et al. [18] in GO nanosheets prepared from graphite flakes. Differently, in a similar material [19], there was demonstrated selective sensitivity to $\mathrm{Cu}^{2+}$, and no response to other species, including $\mathrm{Fe}^{3+}$. In GOQDs synthesized with a bottom-up method, fluorescence quenching in the presence of $\mathrm{Hg}^{2+}$ was reported [20], whereas in GQDs synthesized from carbon fibers [22,24], an even more complex situation was observed, with multiple sensitivity to $\mathrm{Co}^{2+}, \mathrm{Mn}^{2+}, \mathrm{Ni}^{2+}$, and $\mathrm{Cu}^{2+}$. Finally, response to $\mathrm{Cr}^{6+}$ was reported by using commercially available GOQDs [23].

The differences in dimensions, content of defects and functional groups, depending on the different methods of preparation and starting compound for GOQDs, could account for the reported variety of results [32]. In any case, this situation is not helped by designing a single sensing system able to reliably differentiate between several metal species. With the aim of using a starting compound with a more defined structure and molecular weight, we have recently studied a novel type of graphene-like nanoparticle [33], synthesized by oxidation and cage-opening of $C_{60}$ fullerene [34]. These unfolded fullerene quantum dots (UFQDs), showed reproducible fluorescence quenching in the presence of $\mathrm{Cu}^{2+}, \mathrm{As}(\mathrm{III})$, and $\mathrm{Pb}^{2+}$.

In the present work, the study has been extended to a larger number of cations since $\mathrm{Cd}^{2+}$, $\mathrm{As}(\mathrm{V})$, and $\mathrm{Ca}^{2+}$ have been added to the ensemble of $\mathrm{As}(\mathrm{III}), \mathrm{Hg}^{2+}, \mathrm{Fe}^{2+}, \mathrm{Cu}^{2+}, \mathrm{Ni}^{2+}, \mathrm{Pb}^{2+}, \mathrm{Co}^{2+}$, and $\mathrm{Na}^{+}$previously investigated. This allowed us to observe that cadmium ions produce a remarkable negative quenching, that is a fluorescence enhancement, which had never been found in regular GOQDs. In addition, and more importantly, the usual measurements of fluorescence quenching have been integrated with accurate recording of the variations of the optical absorption spectra upon titration. This strategy allowed a peculiar combination of two calibration curves, which presents unique characteristics for each species. Time-resolved fluorescence lifetime measurements have been carried out in order to get more insight on the physical origin of the sensitivity to the different cations.

\section{Materials and Methods}

\subsection{Materials}

All chemicals, including $\mathrm{C}_{60}$ buckminsterfullerene (TERM USA, Fort Bragg, CA, USA), sodium hydroxide (Carlo Erba, Milano, Italy), sulphuric acid (99.9\%, Sigma Aldrich, Milano, Italy), potassium permanganate (Sigma Aldrich), sodium nitrate (Sigma Aldrich), and hydrogen peroxide (Sigma Aldrich) were used as purchased without any further purification. For the measurements of 
sensitivity to metal ions, the metal salt solutions were prepared at the concentration of $200 \mu \mathrm{M}$ in deionized water a few days before use, and stored at $5{ }^{\circ} \mathrm{C}$ to avoid degradation. That was particularly important in the case of salt containing arsenic(V), which tends to reduce to arsenic(III) [35]. The salt solutions were then diluted to the appropriate values of concentration for the measurements.

\subsection{Synthesis of UFQDs}

Unfolded fullerene quantum dots (UFQDs) were synthesized by using a modification of classical Hummer method [36], as previously reported [34]. The oxidation and opening of the C60 structure was possible thanks to strong oxidant agents and to temperature variations. The reaction was stopped with the addition of $\mathrm{H}_{2} \mathrm{O}_{2}$, and concentrated $\mathrm{NaOH}$ was used to acquire a solution at $\mathrm{pH}$ 8. The final product was dialyzed with a retained molecular weight of $2000 \mathrm{Da}$ for two days to remove the extra acid and salt. After dialysis, the solution was diluted 1:5 with deionized water to obtain the stock solution. By drying the solution, the unfolded fullerene weight concentration of the stock solution was estimated to be about $0.2 \mathrm{mg} / \mathrm{mL}$. In order to study and take account of the reproducibility of synthesis, the entire preparation procedure was repeated 10 times on different days over a 6 month period.

\subsection{Instrumentation and Procedure for Detection of Heavy Metal Ions}

Fourier transform infrared spectroscopy (FT-IR) data were obtained on powders by a Perkin Elmer Spectrum One spectrometer (Waltham, MA, USA). ${ }^{13} \mathrm{C}-\mathrm{NMR}$ spectra were recorded with a Bruker Avance 300 spectrometer (Bruker Corp., Billerica, MA, USA). The surface analyses were carried in an electronic spectrometer Escalab MkII (VG Scientific Ltd., London, UK) equipped with XPS and AES techniques. The $\mathrm{Al} \mathrm{K} \alpha$ source was used for the photoemission and X-ray induced Auger spectroscopy, whereas a LEG200 electron gun was used for the AES. The photoemission spectra were collected at $50 \mathrm{eV}$ pass energy in selected area mode $\mathrm{A} 3 \times 10$ with a diameter of $\approx 3 \mathrm{~mm}$, whereas the Auger spectra were registered at the pass energy of $100 \mathrm{eV}$, in order to increase the signal-to-noise ratio. All experimental data were processed by using the software Avantage v.5 (Thermo Fisher Scientific, Waltham, MA, USA). Experimental C KVV spectra were smoothed at least for 11 times by moving average routine with a width of $1.2 \mathrm{eV}$. Afterwards, these spectra were differentiated by using a width of 7 data points for the determination of D parameter [37]. Atomic force microscopy (AFM) was carried out in tapping mode (AC) with Si tip (spring constant around $40 \mathrm{~N} / \mathrm{m}$ ) on freshly cleaved Mica substrate after the deposition (and drying) of UFQD in aqueous solution. A digital $\mathrm{pH}$ meter (Hanna Instruments, Padova, Italy) was used to check the $\mathrm{pH}$ of the solutions. UV-vis absorption spectra were recorded with a Cary 50 spectrophotometer (Varian Inc., Palo Alto, CA, USA, USA) by using fused silica cuvettes with $10 \mathrm{~mm}$ optical path. Photoluminescence (PL) spectra were acquired on a laboratory set-up [38] equipped with an emission $25 \mathrm{~cm}$ monochromator (Cornerstone 260, Oriel Instruments, Stratford, CT, USA), specific excitation-rejection filters, and a R3896 photomultiplier (Hamamatsu Photonics Corporation, Bridgewater, NJ, USA), by using an optical length of $10 \mathrm{~mm}$ in a standard $90^{\circ}$ geometry to reduce the effective sample length experienced by both the excitation and the emission light to $0.5 \mathrm{~mm}$, approximately. In this way, it was possible to reduce artefacts in the PL quenching due to inner filter effects and transmittance variations [22]. The optical characterization of UFQDs was performed by using a $200 \mathrm{~W}$ continuous $\mathrm{Hg}(\mathrm{Xe})$ discharge lamp (Oriel Corp.) as optical source, with an excitation $25 \mathrm{~cm}$ monochromator (Photon Technology International, Inc., Birmingham, NJ, USA) and appropriate optical filters. The PL quenching by metal ions, instead, was characterized by using a $10 \mathrm{~mW}$ continuous wave LED at $300 \mathrm{~nm}$ (Thorlabs Inc., Newton, NJ, USA). The spectral response of the set up for PL detection was calibrated over the visible spectral range with a reference fluorophore solution. This enabled the fully correction of the emission curves. A spectral bandpass of $3 \mathrm{~nm}$ was used for both the excitation and emission monochromators. Fluorescence decay curves were recorded in a single photon counting spectrofluorometer (Fluoromax-4, Horiba, Irvine, CA, USA), and data were corrected both for dilution and for inner filter effects. The response to metal ions was characterized against a reference (blank) solution which was prepared by mixing $1.5 \mathrm{~mL}$ of the 
stock solution with $1.5 \mathrm{~mL}$ of deionized water. The measurements in the presence of metal ions were performed after adding $1.5 \mathrm{~mL}$ of the stock solution to the same volume of the metal-salt water solution at the appropriate concentration.

\section{Results and Discussion}

\subsection{Morphological and Optical Characterization of UFQDs}

AFM images of the dried stock solution (Figure 1a,b) showed particles with lateral dimensions of $15 \mathrm{~nm}$, approximately, and height of about $0.5-2 \mathrm{~nm}$, consistently with values observed in GO and graphene nanoparticles $[39,40]$. In particular, the lateral dimensions indicated that the aggregation of UFQDs occurred during solvent evaporation [34] (the tip convolution effect cannot exceed an enlargement more than 1-2 nm for the measured height). In fact, transmission electron microscopy analysis and dynamic light scattering measurements (DLS) previously performed on the same samples [33] (not reported here) showed the presence of a uniform dispersion of UFQDs nanoparticles with lateral dimensions ranging from 2 to $4 \mathrm{~nm}$. The XPS spectrum of $C 1$ s region reported in (Figure 1c) testified the prevalence of $\mathrm{C}-\mathrm{C}$ bonds (component $\mathrm{A}$ ) with binding energy $(\mathrm{BE})=284.6 \mathrm{eV}$ [37]. Other two minor components of $\mathrm{C} 1$ s peak are attributed to $\mathrm{C}-\mathrm{O}$ bonds, with $\mathrm{BE}=286.4 \mathrm{eV}$, and carboxylic bonds with $\mathrm{BE}=288.6 \mathrm{eV}$. From the spectra of $\mathrm{C}$, the KVV region was acquired by using X-rays and electron beam (see Figure 1d), and the values of D parameter were determined to 12.7 and $20.9 \mathrm{eV}$, respectively. This change of the $\mathrm{D}$ parameter from the diamond-like value obtained with $\mathrm{X}$-rays to graphitic one with electron beam indicates that the main configuration of $\mathrm{C}-\mathrm{C}$ bonds corresponds to graphene [37,41]. The FT-IR and ${ }^{13} \mathrm{C}$ NMR spectra (reported in Ref. [33]) presented similar features to those found in GOQDs, and the open-cage fullerene QDs [15,19,34,42,43]. In particular, the FT-IR spectrum showed the $C=C$ vibration, that can be attributed to the presence of carboxylic acid and hydroxyl groups in the carbon nanoparticles. With regard to the optical properties, the stock solution was clear, with a slight brownish color, and did not show appreciable Tyndall effect with a He-Ne laser pointer, while a visible blue photoluminescence appeared under illumination with a $365 \mathrm{~nm}$ Wood's lamp (Figure 2a). These characteristics have remained stable for at least one year at room temperature. The fluorescence and the absorption spectra (Figure 2b) showed the characteristic spectral features found in regular GOQDs synthesized either from graphite or from citric acid with a bottom-up procedure [17-24]. In particular, the UV-vis absorbance spectrum exhibited the typical well-resolved peak at $230 \mathrm{~nm}$, generally attributed to the $\pi-\pi^{*}$ transition of the aromatic $\mathrm{sp}^{2}$ domains, and one more peak at $\approx 305 \mathrm{~nm}$, which is due to the $\mathrm{n}-\pi^{*}$ transition in $\mathrm{C}=\mathrm{O}$ bonds of oxygen-containing functional groups [12,44]. It should be noted that FT-IR, XPS, and optical spectra of the present UFQDs are particularly similar to those found in so-called reduced graphene oxide (rGO), i.e., after having undergone a physical or chemical reducing process [45-47], thus, with a relatively low content of oxygen-containing functional groups.
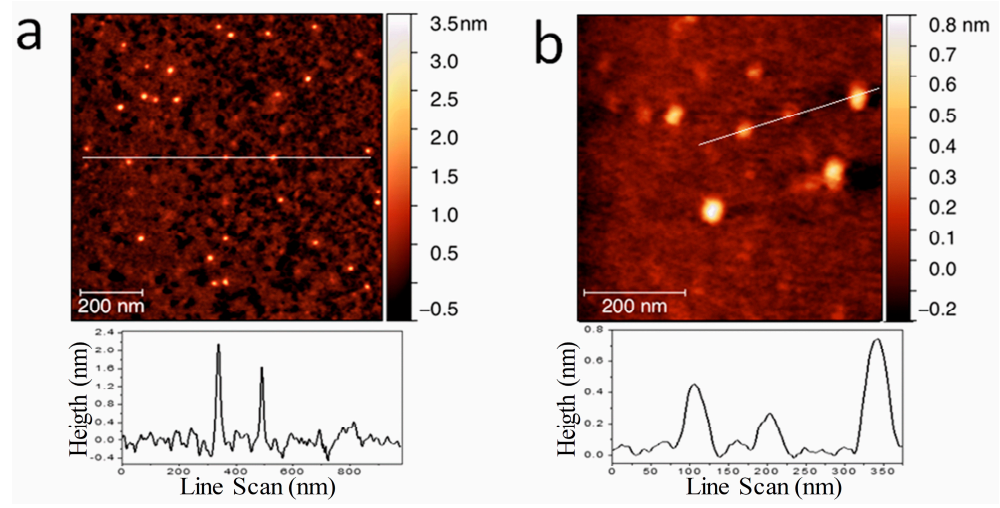

Figure 1. Cont. 

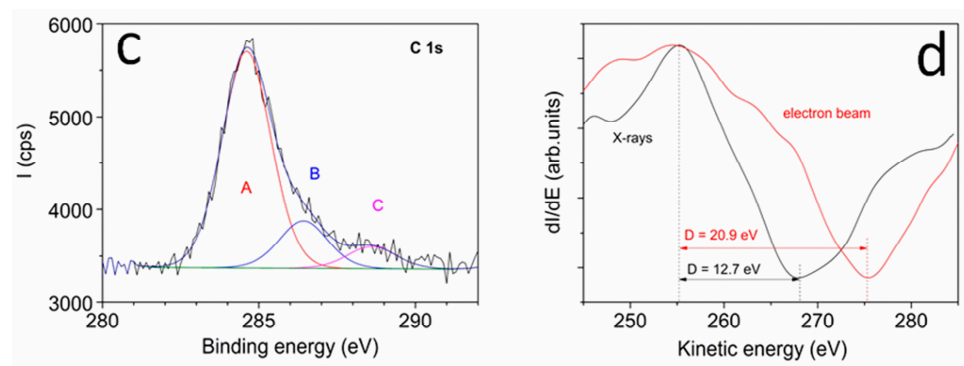

Figure 1. (a) Low-magnification and (b) high-magnification AFM image of unfolded fullerene quantum dots (UFQDs) deposited on the mica substrate and the height profile along the lines indicated in the images; XPS spectrum of C 1 s region (c) and Auger spectrum of C KVV region (d).

This supposedly small number of functional groups, however, seems to have a low effect on the stability of UFQDs in water, since the absorbance of the as-prepared solution (after dialysis) at different degrees of dilution in deionized water showed a linear increase with increasing UFQD volume fraction (see Figure 2c). This indicates that possible concentration effects, due to aggregation or interparticle interactions, are negligible in the entire range of concentration, which is up to 10 times the concentration of the reference solution used for the detection of metal ions. Moreover, the solutions remained stable for months at any value of concentration. These findings, along with the results of DLS previously reported [33], confirmed the model of a monodisperse solution of non-interacting carbon nanosheets.
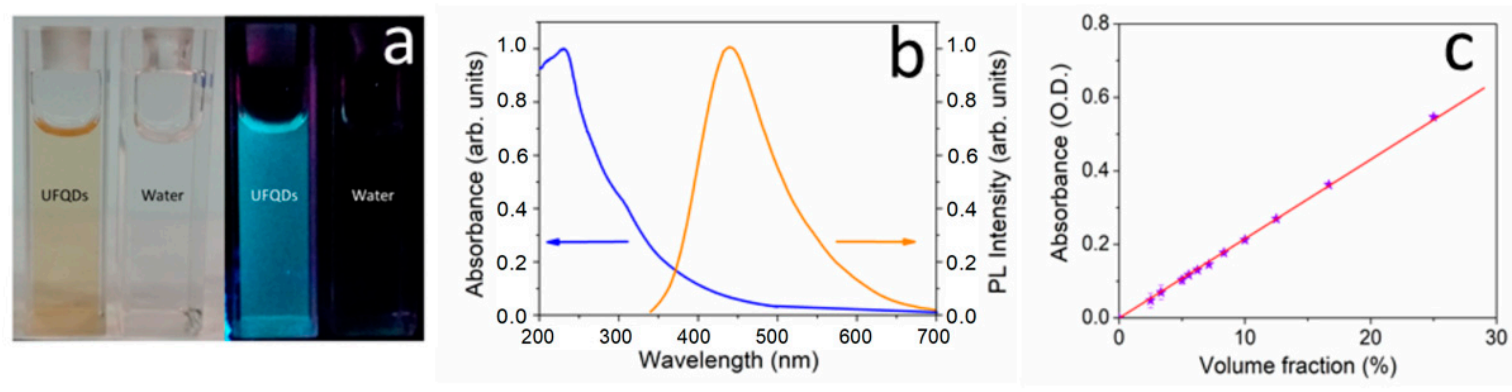

Figure 2. (a) Photograph of UFQD stock solution and deionized (DI) water taken under visible light (left) and $365 \mathrm{~nm}$ UV light (right); (b) Fluorescence and UV-vis absorption spectra of UFQDs stock solution; (c) Optical absorbance at $\lambda_{\mathrm{abs}}=275 \mathrm{~nm}$ of the stock solution diluted at different volume fraction in deionized water.

\subsection{Diversified Optical Response of UFQDs to Heavy Metal Ions}

In line with the literature on regular GOQDs, the optical response of UFQD reference solution was first tested with regard to possible fluorescence variations against the addition of eleven different cations: 9 heavy metal ions, plus $\mathrm{Ca}^{2+}$ and $\mathrm{Na}^{+}$. Figure 3 shows the fluorescence quenching ratio $\mathrm{F}_{0} / \mathrm{F}-1$ in the absence and presence of various ions at a concentration of $100 \mu \mathrm{M}$, extending the data reported in [33] to the results obtained with three new ions: $\mathrm{Cd}^{2+}, \mathrm{Ca}^{2+}$, and $\mathrm{As}(\mathrm{V})$. As can be seen, in addition to the typical fluorescence quenching occurring with $\mathrm{Cu}^{2+}, \mathrm{Pb}^{2+}$, and $\mathrm{As}(\mathrm{III})$, a somehow surprising fluorescence enhancement, or turn-on effect, was observed in the presence of cadmium ions. By recording the UV-vis absorption spectra of the reference solution, we found an even more complex situation, with different degrees of variation of absorbance after the addition of different species. In fact, the combination of the fluorescence quenching and absorption variation was a peculiar property of a specific metal ion. In the following, we will discuss these characteristics for each distinct species. 


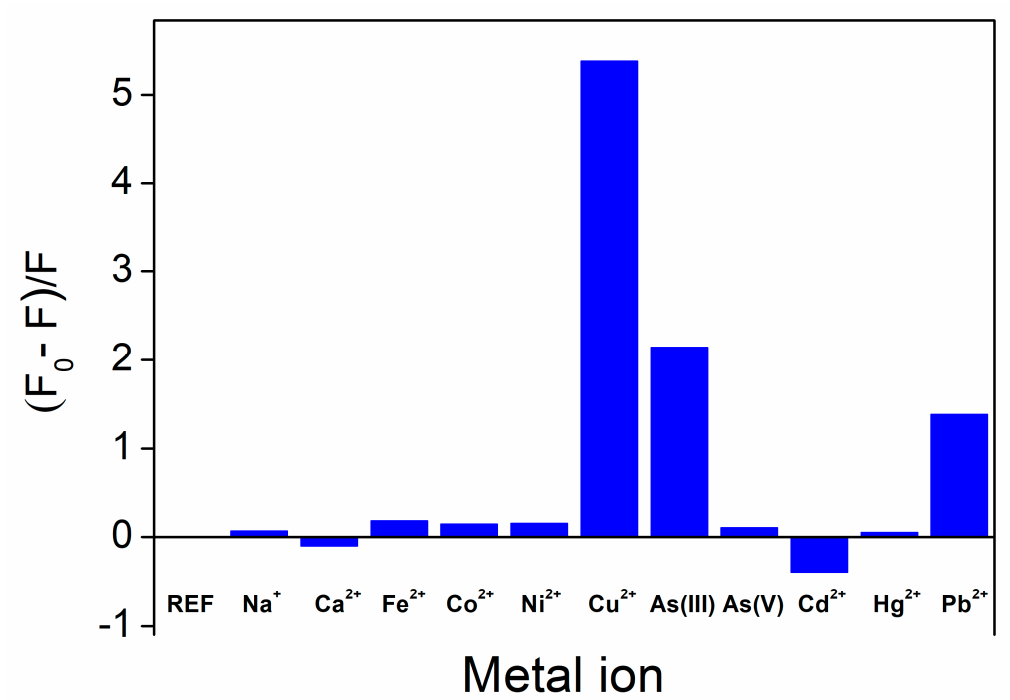

Figure 3. Fluorescence intensity ratio of the UFQD reference solution in the absence (REF) and presence of various metal ions at a concentration of $100 \mu \mathrm{M}$.

First, we will present the remarkable fluorescence enhancement observed in the presence of $\mathrm{Cd}^{2+}$. As displayed in Figure 4a, the progressive addition of cadmium ions to the reference UFQD solution produced the gradual increase of the fluorescence signal $\mathrm{F}$ without any appreciable change of the spectral profile. It should be noted that, to our knowledge, such a fluorescence turn-on effect had never been reported in GOQDs, whereas it is commonly observed in molecular fluorophores and semiconductor quantum dots [48-50]. At the same time, no variations were observed in the absorption spectra, as displayed in Figure $4 \mathrm{~b}$, apart from the progressive rise of the curve below $250 \mathrm{~nm}$, which is clearly due to the increasing concentration of $\mathrm{NO}^{3-}$ ions coming from the added cadmium nitrate. This was checked by measuring the absorbance of a water solution containing only the cadmium salt at $100 \mu \mathrm{M}$ of $\mathrm{Cd}^{2+}$ (dotted lines in Figure $4 \mathrm{~b}$ ). We verified the independence of the quenching effect from the anionic species by measuring a reasonably similar fluorescence turn-on effect with no variation of absorbance in cadmium chloride (see Figure S1 in Supporting Information). In addition, we performed an interference experiment for $\mathrm{Cd}^{2+}$ with some other relevant ions. While, as expected, the addition of cadmium ions to UFQD solution containing non-sensitizing ions such as $\mathrm{Na}^{+}, \mathrm{Ca}^{2+}, \mathrm{Co}^{2+}$, and $\mathrm{Ni}^{2+}$, led to minor variations in the fluorescence enhancement of cadmium, a great variation was found with $\mathrm{Cu}^{2+}$ (see Figure S1 in SI). In fact, cadmium only produced a very low partial recovery of the characteristic quenching effect of copper.
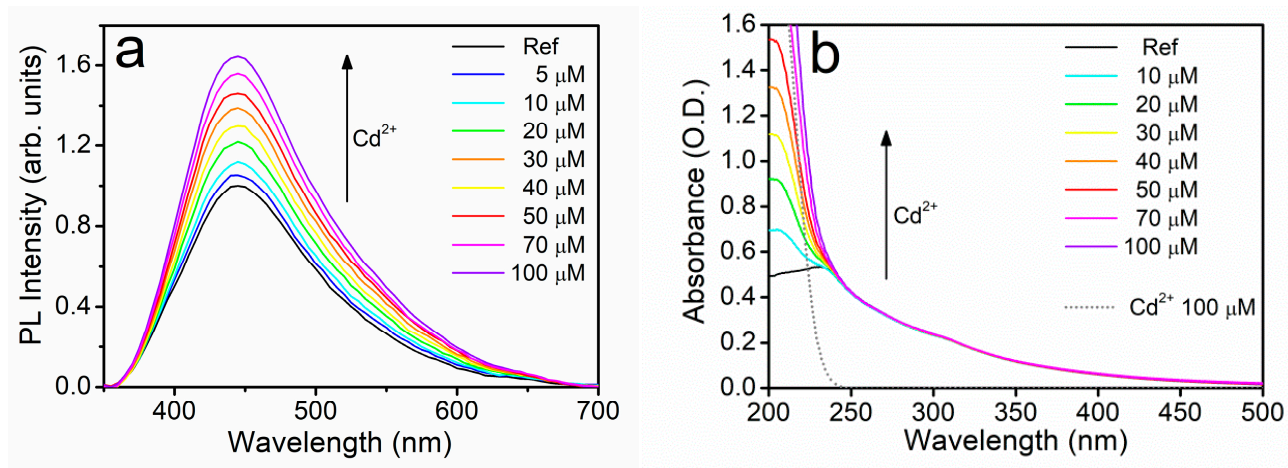

Figure 4. Emission (a) and optical absorption (b) spectra of the reference aqueous suspension of UFQDs in the presence $\mathrm{Cd}^{2+}$ at different concentrations. The absorbance of pure cadmium salt solution in water is also reported (dotted line). 
Quite differently from the case of $\mathrm{Cd}^{2+}$, the progressive addition of $\mathrm{Pb}^{2+}$ produced a typical fluorescence quenching effect, since the fluorescence signal F gradually decreased with the increasing ion concentration (see Figure 5a). This behavior resembles the typical fluorescence quenching effect reported in the literature on regular GOQDs [17-24]. As a further difference with respect to cadmium ions, $\mathrm{Pb}^{2+}$ also modified the absorption of UFQDs, producing a progressive increase of the absorbance in the wavelength range $250-340 \mathrm{~nm}$ (see Figure 5b), with an appreciable smearing of the peak at $300 \mathrm{~nm}$. As discussed in the case of cadmium, this increase of absorbance cannot be attributed to the direct presence of the metal ions added to the solution. Instead, it is necessarily an effect of the interaction between metal ions and carbon layers. As will be discussed in Section 3.3, a static quenching mechanism, arising from the formation of ion-UFQD complexes, can account for this interaction.

The progressive addition of $\mathrm{Cu}^{2+}$ produced a similar response of UFQDs (data not shown here, see Ref. [33]), even though with a slightly higher quenching ratio and a lower increase of the absorption than those observed with $\mathrm{Pb}^{2+}$. Finally, the addition of $\mathrm{As}$ (III) induced a further different optical effect since the fluorescence intensity decreased with increasing metal ion concentration, while no variations were observed in the absorption spectra (see Ref. [33]). Interestingly, UFQDs discriminated As(III) from $\mathrm{As}(\mathrm{V})$, since the latter species did not induce any significant optical variation (see Figure 3).
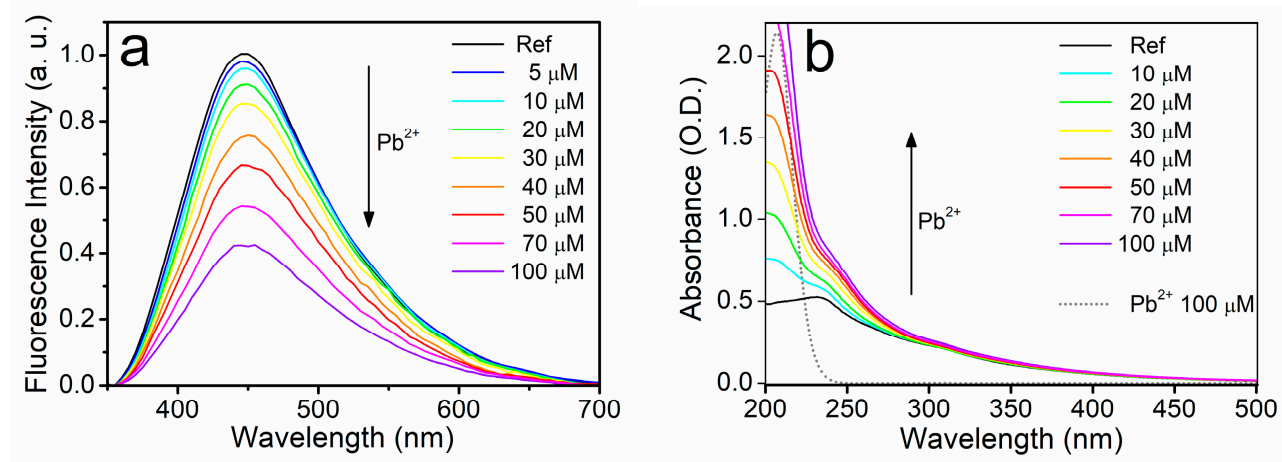

Figure 5. Emission (a) and optical absorption (b) spectra of the reference aqueous suspension of UFQDs in the presence of $\mathrm{Pb}^{2+}$ at different concentrations. The absorbance of pure lead salt solution in water is also reported (dotted line).

The diversification of response of UFQDs to the four sensitizing ions can be clearly seen in Figure 6, which shows the comparison of the different calibration curves obtained from the measurements reported above, and separately displayed for the variation of fluorescence intensity (Figure 6a) and of the optical absorbance (Figure 6b).
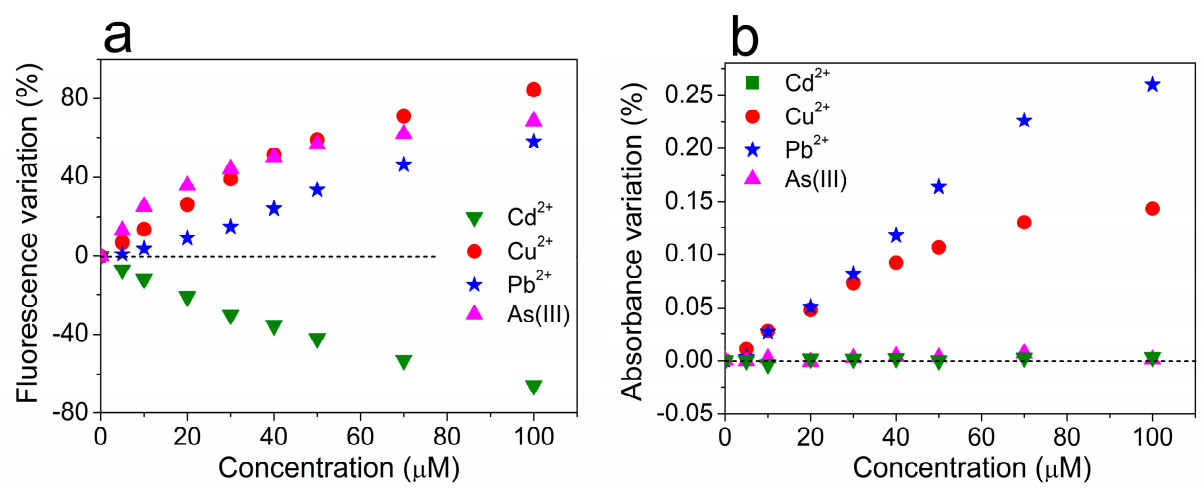

Figure 6. The percentage variation of the fluorescence intensity (a) and optical absorbance at $\lambda_{\mathrm{abs}}=275 \mathrm{~nm}(\mathbf{b})$ of the reference aqueous suspension of UFQDs in the presence of $\mathrm{Cd}^{2+}, \mathrm{Cu}^{2+}$, $\mathrm{Pb}^{2+}$, and $\mathrm{As}(\mathrm{III})$ at various concentrations. 
In summary, three different types of optical response of UFQDs can be observed with regard to the variations of fluorescence and absorption spectra and they are reported in Table 1.

Table 1. The different types of optical response with regard to fluorescence intensity and absorbance in the range 250-340 nm of UFQD reference solution in the presence of heavy metal ions.

\begin{tabular}{ccc}
\hline Sensitizing Ion & Fluorescence Variation & Absorbance Variation \\
\hline $\mathrm{Cu}^{2+}, \mathrm{Pb}^{2+}$ & decrease & increase \\
$\mathrm{As}(\mathrm{III})$ & decrease & steady \\
$\mathrm{Cd}^{2+}$ & increase & steady \\
\hline
\end{tabular}

Time-resolved fluorescence lifetime study can help understand the physical processes responsible for fluorescence and absorption variations. Figure 7 shows the fluorescence decays of UFQDs after a pulsed excitation at $280 \mathrm{~nm}$ in the absence and in the presence of the different metal ions at a concentration of $100 \mu \mathrm{M}$. All the decay curves were well fitted using tri-exponential functions having short $\left(\tau_{1}\right)$, medium $\left(\tau_{2}\right)$, and long $\left(\tau_{3}\right)$ lifetime components, with respective weight coefficients $A_{i}$ (see Table 2). These components can be related to optical transitions originating from different fluorescent sites of carbon nanoparticles [12-16,51]. For all the fluorescence-quenching species of the present study, i.e., $\mathrm{Cu}^{2+}, \mathrm{Pb}^{2+}$ and $\mathrm{As}(\mathrm{III})$, the quenched-fluorescence lifetimes were not decreased in comparison to reference, thus confirming the occurrence of static quenching through complexation of the metal ions, rather than dynamic quenching through collisional deactivation. In particular, $\mathrm{Cu}^{2+}$ and $\mathrm{Pb}^{2+}$ slightly increased the values of all the lifetime components, and mainly decreased the weight of the shortest components $\mathrm{A}_{1}$ and $\mathrm{A}_{2}$, thus resulting in an appreciably slower overall decay. Differently, As(III) evenly decreased the weight of all the components, whereas $\mathrm{Cd}^{2+}$ mainly increased the weight of $\tau_{2}$ and shortened the slowest component $\tau_{3}$, producing a peculiar faster decay in the long time region. We note that these three types of time responses paralleled the steady-state optical behavior described in Table 1.

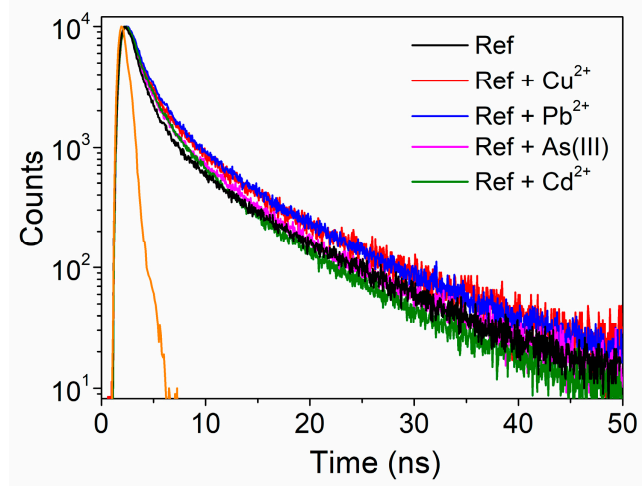

Figure 7. Fluorescence decay of UFQDs in the absence (black line) and presence (colored lines) of the metal ions $\left(\lambda_{\mathrm{exc}}=280 \mathrm{~nm}\right)$. Instrumental response function is represented by the orange line.

Table 2. Values of the lifetime components $\tau_{i}$ and the respective weight constants $A_{i}$ of the three-exponential fit of the fluorescence decay in the absence (REF) and the presence of the different metal ions. $A_{i}$ values are normalized to those of the reference solution.

\begin{tabular}{ccccccc}
\hline & $\boldsymbol{\tau}_{\mathbf{1}}$ (ns) & $\mathbf{A}_{\mathbf{1}}$ & $\boldsymbol{\tau}_{\mathbf{2}}$ & $\mathbf{A}_{\mathbf{2}}$ & $\boldsymbol{\tau}_{\mathbf{3}}$ & $\mathbf{A}_{\mathbf{3}}$ \\
\hline $\mathrm{REF}$ & 0.557 & 1 & 2.404 & 1 & 10.30 & 1 \\
$\mathrm{Cu}^{2+}$ & 0.648 & 0.30 & 3.06 & 0.35 & 11.35 & 0.5 \\
$\mathrm{~Pb}^{2+}$ & 0.685 & 0.68 & 2.94 & 1.05 & 10.69 & 1 \\
$\mathrm{As}(\mathrm{III})$ & 0.602 & 0.45 & 2.99 & 0.55 & 10.30 & 0.6 \\
$\mathrm{Cd}^{2+}$ & 0.629 & 1.37 & 2.74 & 1.90 & 9.55 & 1.5 \\
\hline
\end{tabular}




\subsection{Possible Mechanisms for the Optical Response}

The variations of fluorescence steady-state intensity, with substantially unvaried fluorescence lifetimes, and the modifications of absorption spectra in the range $250-340 \mathrm{~nm}$ can both be explained by the interaction of metal ions with UFQDs through formation of stable complexes. This mechanism had already been proposed for fluorescence quenching in regular GOQDs [20-22]. Moreover, several studies on GOQDs and GO have investigated the aggregation processes that occur via multiple complexation, i.e., with the metal ions binding more carbon layers together through coordination with the various oxygen-containing dangling groups [52-56]. As displayed in Scheme 1, GOQDs and UFQDs possibly have different lattice structure, but certainly share the presence of carboxyl, hydroxyl, and epoxy groups, as discussed in Section 3.1. Photoinduced electron transfer (PET) mechanisms are generally considered to play a significant role in the interaction of metal ions with the molecular orbitals of the functional groups [21,22,49]. Within this framework, the extensive literature on the metal adsorption by carbon nanomaterials [54,57-61] suggests that the three distinct types of optical responses observed in present UFQDs can be explained with combinations of the properties of the metal ions and the affinity with different sites or oxygen-containing groups [62].
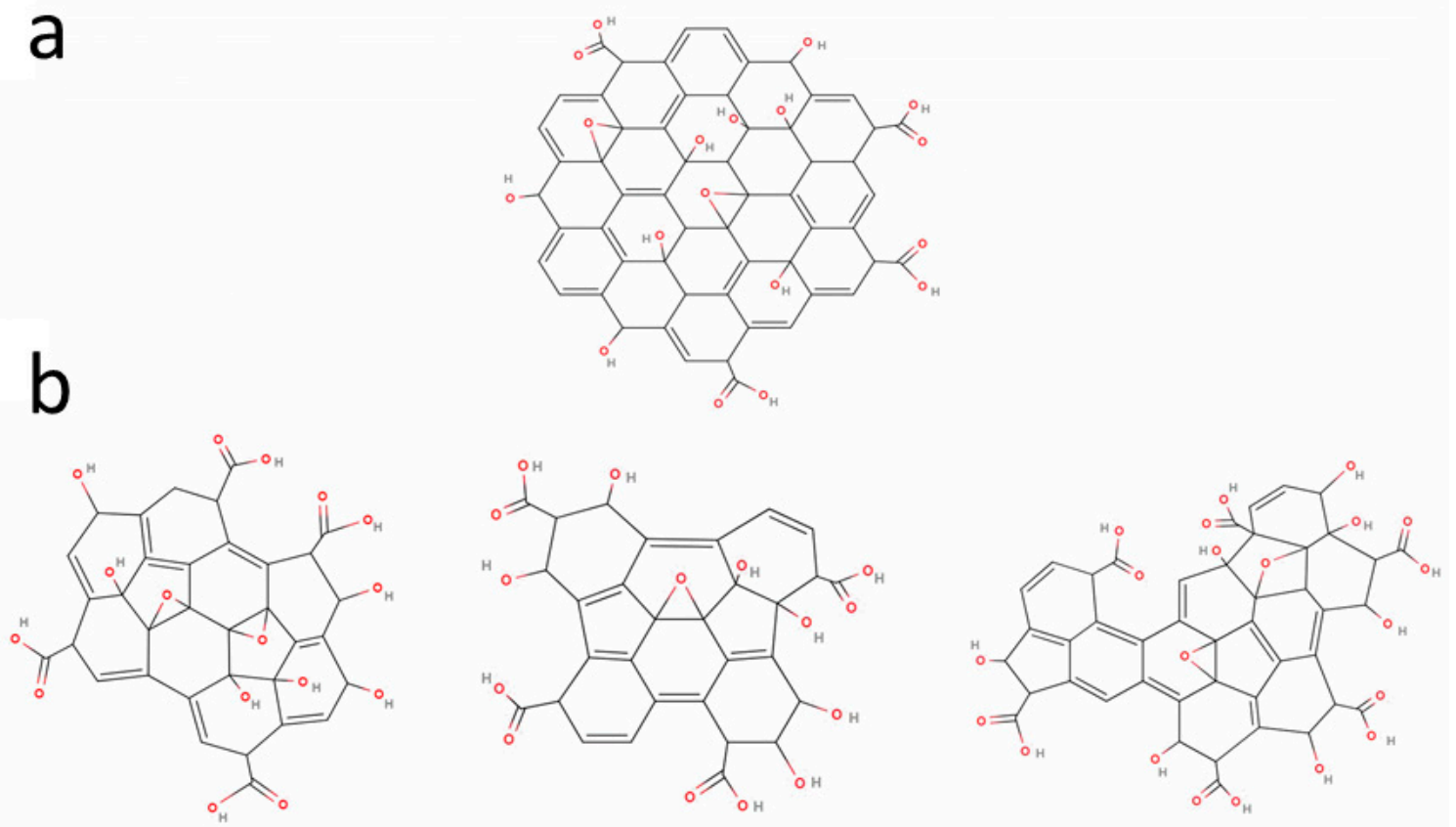

Scheme 1. (a) Structure of graphene oxide (GO) nanoparticles compared with (b) possible structures of UFQD nanosheets.

The fluorescence quenching with increase of absorption, observed with $\mathrm{Cu}^{2+}$ and $\mathrm{Pb}^{2+}$, can be explained with the metal ions binding to UFQDs through the carboxyl groups located at the edges, possibly promoting an edge-to-edge aggregation of UFQDs [52,53,57,59,62], as displayed in Scheme S1a of Supporting Information. The different response observed after the addition of As(III) could be due to the fact that arsenic is known to bind with the surface of the carbon nanosheets, rather than the edge [63]. As a consequence, face-to-face stacking (see Scheme S1b) could occur, and this would quench fluorescence through radiationless decay mechanisms of the excited state [55], without altering the absorption spectrum. Finally, the noteworthy fluorescence enhancement observed with $\mathrm{Cd}^{2+}$ resembled the fluorescence turn-on effect frequently observed in molecular fluorophores after chelating this ion, and is referred to as "chelation-enhanced fluorescence" (CHEF). CHEF is generally attributed to a peculiar mechanism of interaction, involving PET processes of the fluorescent ligand [49]. Briefly, $\mathrm{Cd}^{2+}$ might coordinate with the basal surface of the carbon layers trough cation- $\pi$ 
interaction [64] using the oxygen lone pair electrons of the carbonyl and epoxy groups that, in the absence of the cadmium ion, would instead fill the empty states left by the optical excitation and reduce the radiative recombination rate (see Scheme S2 in SI). Therefore, by immobilizing the lone pair electrons, $\mathrm{Cd}^{2+}$ increases the recombination rate and the fluorescence intensity of UFQDs. This model is consistent with the decrease of $\tau_{3}$ reported in Section 3.1 and face-to-face stacking, similar to As(III).

\subsection{Comparison with Regular GOQDs, LODs, and Three-Dimensional Calibration Diagram}

More investigations are required to confirm the hypothesis made in the previous paragraph about the origin of the different optical behaviors of UFQDs. However, we note that sensitivity of a single solution to more metal ions was previously observed only in GOQDs synthesized from carbon fibers [22,24] which showed fluorescence quenching to seven metal ions, including $\mathrm{Cu}^{2+}, \mathrm{Ni}^{2+}$, and $\mathrm{Co}^{2+}$. In addition, it should be pointed out that neither the response to As(III) nor the remarkable fluorescence enhancement observed with the addition of $\mathrm{Cd}^{2+}$ have ever been reported in regular GOQDs. In the present experiment, from the calibration curves of Figure 6 in the low concentration limit, the following limits of detection (LODs) can be estimated, according to the IUPAC definition [65]: $350 \mathrm{nM}, 1 \mu \mathrm{M}, 500 \mathrm{nM}$, and $350 \mathrm{nM}$ for $\mathrm{Cu}^{2+}, \mathrm{Pb}^{2+}, \mathrm{As}(\mathrm{III})$, and $\mathrm{Cd}^{2+}$, respectively. While these values are in line with those reported in the literature for regular GOQDs [18-20,22,24], only the LOD for $\mathrm{Cu}^{2+}$ is well below the current limit of $30 \mu \mathrm{M}$ suggested by WHO for drinking water, and thus, meets the fundamental requirement for a real sensing material. Conversely, the present values are definitely much higher than the limits of $50 \mathrm{nM}$ for lead and $14 \mathrm{nM}$ for arsenic. In this regard, it should be noted that neither regular GOQDs nor present UFQDs reach the LODs in the picomolar range achieved by some specifically engineered molecular chromophores [31] which, however, rarely exhibit multiple sensitivity to different ions. With specific regard to $\mathrm{Cd}^{2+}$, large fluorescence turn-on effects can occur in molecular chromophores due to PET mechanisms interacting with rearrangements of the molecular structure [31], and this can lead to LODs as low as $0.1 \mathrm{pM}$ [66]. However, in most of the molecular sensors reported in the literature, values in the nanomolar range, reasonably comparable to the present ones, are reported $[48,67]$. On the other hand, as discussed in the introduction, few experimental works have been carried out so far on the peculiar properties of carbon nanomaterials, i.e., the multiple sensitivity of fluorescence quenching with simultaneous variation of absorbance.

With regard to the selectivity, we note that while the calibration curves of Figure 6 clearly show the variety of response of UFQDs towards the different ions, they do not directly help identify the distinct species. For instance, at low concentration, the variation of absorption in the presence of $\mathrm{Pb}^{2+}$ is practically indistinguishable from that of $\mathrm{Cu}^{2+}$, while both $\mathrm{Cd}^{2+}$ and $\mathrm{As}(\mathrm{III})$ steadily produce no variation at all (Figure 6b). Similarly, in the range of concentrations from 30 to $50 \mu \mathrm{M}$, the fluorescence quenching produced by $\mathrm{As}(\mathrm{III})$ almost equals that given by $\mathrm{Cu}^{2+}$ (Figure 6a). However, the two sets of measurements can be combined together to provide the more informative three-dimensional calibration diagram (3DCD) of Figure 8. In 3DCD, the results of titration measurements are reported in a 3D space, with the $Z$ axis representing the concentration of each ion while the $X$ and the $Y$ axes report the variation of fluorescence and absorption, respectively. We note that in this space, the data referring to $\mathrm{Cd}^{2+}$ and $\mathrm{As}(\mathrm{III})$ are in the $\mathrm{XZ}$ plane, since these two ionic species do not produce any variation of absorption. On the other hand, the points relative to cadmium are in the negative semispace of fluorescence quenching. More importantly, datasets of different ions do not cross each other, differently from what occurs in Figure 6, thus demonstrating that a certain species at a given concentration produces a specific couple of values of fluorescence quenching and variation of absorption. In other words, through this three-dimensional plot, the measurement of a certain pair of values of the two optical quantities uniquely determines the concentration of a specific metal ion, as shown with two practical examples in Figure S2 of SI. This property of UFQDs, in principle, can give selectivity to the process of ion detection, and is a promising feature for developing a multiple selective optical detection of heavy metals in aqueous media. 


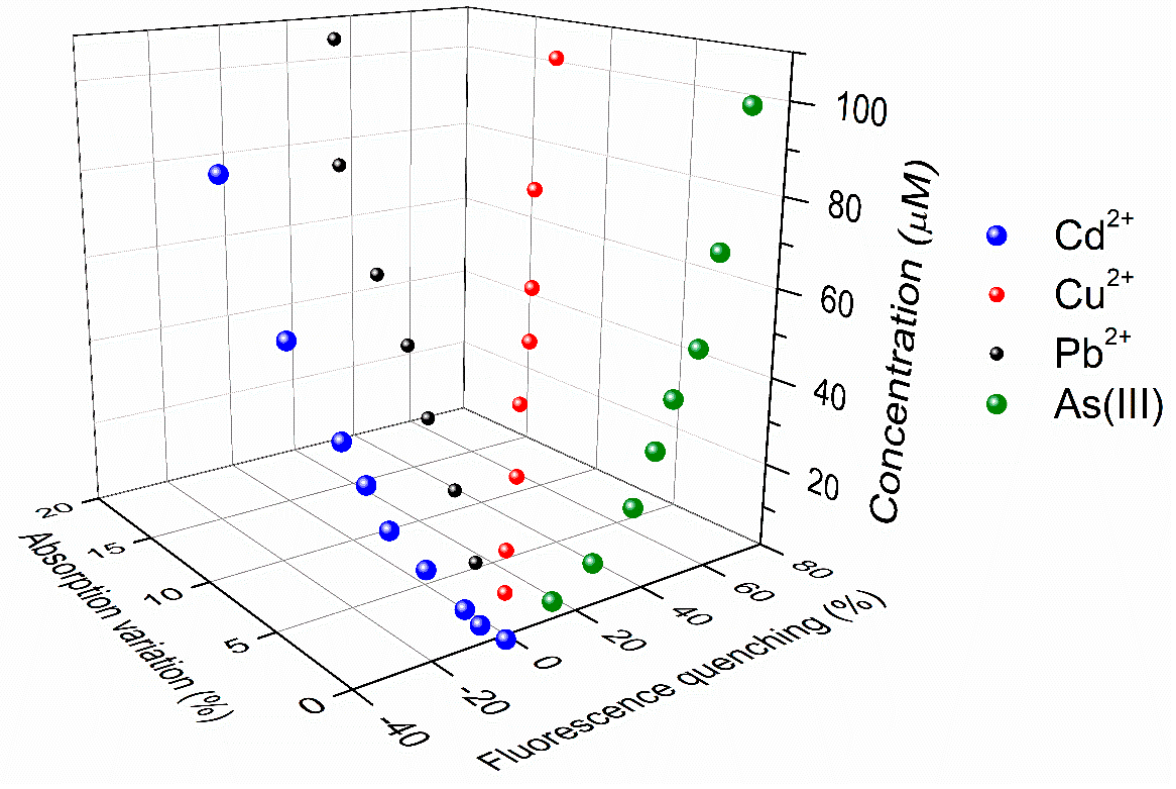

Figure 8. In the three-dimensional graph, the concentration of a specific ionic species is reported as a function of the fluorescence variation and the relative increase of absorbance it produces on UFQDs.

\section{Conclusions}

In conclusion, by recording the variation induced in both fluorescence and optical absorption spectra, we have found that UFQDs exhibited a more complex and diversified behavior than the fluorescence quenching already reported in the literature for regular GOQDs. In fact, different types of optical response were detected to four ions: $\mathrm{Pb}^{2+}, \mathrm{Cu}^{2+}, \mathrm{Cd}^{2+}$, and $\mathrm{As}(\mathrm{III})$. In addition to different degrees of fluorescence quenching in the presence of $\mathrm{Pb}^{2+}, \mathrm{Cu}^{2+}$, and $\mathrm{As}(\mathrm{III})$, appreciable variations of absorption were also revealed with $\mathrm{Pb}^{2+}$ or $\mathrm{Cu}^{2+}$, whereas a remarkable fluorescence enhancement was detected with $\mathrm{Cd}^{2+}$. This last result, in particular, represented the first evidence of fluorescence turn-on effect in non-functionalized carbon-based sensing. Fluorescence lifetime measurements and $\mathrm{pH}$ dependence of fluorescence variations confirmed that, in all cases, the response is due to metal ions forming stable complexes with carbon layers, possibly through distinct type of chemical bonds and binding sites. More investigations, however, are needed to understand how these processes produce differences in the optical outcome. In view of applications to real sensing systems, the LODs for $\mathrm{Pb}^{2+}, \mathrm{Cd}^{2+}$, and $\mathrm{As}(\mathrm{III})$ are definitely too high in comparison with the current limits of WHO, and further steps are needed to meet this fundamental requirement. To this end, we think that the noteworthy property of UFQDs, i.e., the diversification of the optical response towards different ions, deserves more studies in view of the chance of differentiating distinct species through fluorescence and absorption measurements. In principle, this characteristic is the key for the implementation of a selective multiple optical sensor.

Supplementary Materials: The following are available online at http:/ /www.mdpi.com/1424-8220/18/5/1496/ s1, Figure S1: Interference of fluorescence quenching ratio of UFQD reference solution with cadmium in the presence of various metal ions:, Scheme S1: Possible mechanisms of aggregation of UFQDs; rom carbonyl and hydroxyl groups, Scheme S2: Schematic of the chelation enhanced fluorescence (CHEF) process; Figure S2: Two examples of applications of the three-dimensional calibration diagram.

Author Contributions: Conceptualization, R.P. and E.C.; Methodology, P.P.; Validation, P.P., R.P. and E.C.; Formal Analysis, E.C.; Investigation, E.C., S.K., L.S., P.S. and E.P.; Resources, P.T. and C.L.; Writing-Original Draft Preparation, E.C.; Writing-Review \& Editing, R.P.; Supervision, R.P.; Project Administration, R.P.; Funding Acquisition, P.P.

Conflicts of Interest: The authors declare no conflict of interest. 


\section{References}

1. Barreto, J.A.; O’Malley, W.; Kubeil, M.; Graham, B.; Stephan, H.; Spiccia, L. Nanomaterials: Applications in cancer imaging and therapy. Adv. Mater. 2011, 23, H18-H40. [CrossRef] [PubMed]

2. Lin, N.; Huang, J.; Dufresne, A. Preparation, properties and applications of polysaccharide nanocrystals in advanced functional nanomaterials: A review. Nanoscale 2012, 4, 3274. [CrossRef] [PubMed]

3. Prosposito, P.; Mochi, F.; Ciotta, E.; Casalboni, M.; de Matteis, F.; Venditti, I.; Fontana, L.; Testa, G.; Fratoddi, I. Hydrophilic silver nanoparticles with tunable optical properties: Application for the detection of heavy metals in water. Beilstein J. Nanotechnol. 2016, 7, 1654-1661. [CrossRef] [PubMed]

4. Guo, S.; Wang, E. Noble metal nanomaterials: Controllable synthesis and application in fuel cells and analytical sensors. Nano Today 2011, 6, 240-264. [CrossRef]

5. Yadav, A.; de Angelis, R.; Casalboni, M.; de Matteis, F.; Prosposito, P.; Nanni, F.; Cacciotti, I. Spectral properties of self-assembled polystyrene nanospheres photonic crystals doped with luminescent dyes. Opt. Mater. 2013, 35, 1538-1543. [CrossRef]

6. Orsini, A.; Medaglia, P.G.; Scarpellini, D.; Pizzoferrato, R.; Falconi, C. Towards high-performance, low-cost quartz sensors with high-density, well-separated, vertically aligned $\mathrm{ZnO}$ nanowires by low-temperature, seed-less, single-step double-sided growth. Nanotechnology 2013, 24, 355503. [CrossRef] [PubMed]

7. Shen, J.; Zhu, Y.; Yang, X.; Li, C. Graphene quantum dots: Emergent nanolights for bioimaging, sensors, catalysis and photovoltaic devices. Chem. Commun. 2012, 48, 3686-3699. [CrossRef] [PubMed]

8. Yang, X.; Liu, M.; Yin, Y.; Tang, F.; Xu, H.; Liao, X. Green, Hydrothermal Synthesis of Fluorescent Carbon Nanodots from Gardenia, Enabling the Detection of Metronidazole in Pharmaceuticals and Rabbit Plasma. Sensors 2018, 18, 964. [CrossRef] [PubMed]

9. Zhang, J.; Yu, S. Carbon dots: Large-scale synthesis, sensing and bioimaging. Biochem. Pharmacol. 2016, 19, 382-393. [CrossRef]

10. Sun, H.; Wu, L.; Wei, W.; Qu, X. Recent advances in graphene quantum dots for sensing. Mater. Today 2013, 16, 433-442. [CrossRef]

11. Zor, E.; Morales-Narváez, E.; Zamora-Gálvez, A.; Bingol, H.; Ersoz, M.; Merkoçi, A. Graphene quantum dots-based photoluminescent sensor: A multifunctional composite for pesticide detection. ACS Appl. Mater. Interfaces 2015, 7, 20272-20279. [CrossRef] [PubMed]

12. Naumov, A.V. Optical Properties of Graphene Oxide, in Graphene Oxide: Fundamentals and Applications; John Wiley \& Sons, Ltd.: Chichester, UK, 2016.

13. Sk, M.A.; Ananthanarayanan, A.; Huang, L.; Lim, H. Revealing the tunable photoluminescence properties of graphene quantum dots. J. Mater. Chem. C Mater. Opt. Electron. Devices 2014, 2, 6954-6960. [CrossRef]

14. Cao, L.I.; Meziani, M.J.; Sahu, S. Photoluminescence Properties of Graphene versus Other Carbon Nanomaterials. Acc. Chem. Res. 2012, 46, 171-180. [CrossRef] [PubMed]

15. Li, M.; Cushing, S.K.; Zhou, X.; Wu, N. Fingerprinting photoluminescence of functional groups in graphene oxide. J. Mater. Chem. 2012, 22, 23374-23379. [CrossRef]

16. Galande, C.; Mohite, A.D.; Naumov, A.V.; Gao, W.; Ci, L.; Ajayan, A.; Gao, H.; Srivastava, A.; Weisman, R.B.; Ajayan, P.M. Quasi-Molecular Fluorescence from Graphene Oxide. Sci. Rep. 2011, 85, 1-5. [CrossRef] [PubMed]

17. Ju, J.; Chen, W. Graphene Quantum Dots as a Fluorescence Probes for Sensing Metal Ions: Synthesis and Applications. Curr. Org. Chem. 2015, 19, 1150-1162. [CrossRef]

18. Wang, D.; Wang, L.; Dong, X.; Shi, Z.; Jin, J. Chemically tailoring graphene oxides into fluorescent nanosheets for $\mathrm{Fe}^{3+}$ ion detection. Carbon 2012, 50, 2147-2154. [CrossRef]

19. Wang, F.; Gu, Z.; Lei, W.; Wang, W.; Xia, X.; Hao, Q. Graphene quantum dots as a fluorescent sensing platform for highly efficient detection of copper(II) ions. Sens. Actuators B Chem. 2014, 190, 516-522. [CrossRef]

20. Chakraborti, H.; Sinha, S.; Ghosh, S.; Kalyan, S. Interfacing water soluble nanomaterials with fluorescence chemosensing: Graphene quantum dot to detect $\mathrm{Hg}^{2+}$ in $100 \%$ aqueous solution. Mater. Lett. 2013, 97, 78-80. [CrossRef]

21. Li, Z.; Wang, Y.; Ni, Y.; Kokot, S. A rapid and label-free dual detection of $\mathrm{Hg}$ (II) and cysteine with the use of fluorescence switching of graphene quantum dots. Sens. Actuators B Chem. 2015, 207, 490-497. [CrossRef] 
22. Huang, H.; Liao, L.; Xu, X.; Zou, M.; Liu, F.; Li, N. The electron-transfer based interaction between transition metal ions and photoluminescent graphene quantum dots (GQDs): A platform for metal ion sensing. Talanta 2013, 117, 152-157. [CrossRef] [PubMed]

23. Huang, S.; Qiu, H.; Zhu, F.; Lu, S.; Xiao, Q. Graphene quantum dots as on-off-on fluorescent probes for chromium(VI) and ascorbic acid. Microchim. Acta 2015, 182, 1723-1731. [CrossRef]

24. Liu, X.; Gao, W.; Zhou, X. Pristine graphene quantum dots for detection of copper ions. J. Mater. Res. 2014, 29, 1401-1407. [CrossRef]

25. Length, F. Heavy metal pollution and human biotoxic effects. Int. J. Phys. Sci. 2007, 2, 112-118.

26. Jaishankar, M.; Tseten, T.; Anbalagan, N.; Mathew, B.B.; Beeregowda, K.N. Toxicity, mechanism and health effects of some heavy metals. Interdiscip. Toxicol. 2014, 7, 60-72. [CrossRef] [PubMed]

27. Gordon, B.; Callan, P.; Vickers, C. WHO Guidelines for Drinking-Water Quality, 2008th ed.; World Health Organization: Geneva, Switzerland, 2008.

28. Ackerman, A.H.; Creed, P.A.; Parks, A.N.; Fricke, M.W.; Schwegel, C.A.; Creed, J.T.; Heitkemper, D.T.; Vela, N.P. Comparison of a chemical and enzymatic extraction of arsenic from rice and an assessment of the arsenic absorption from contaminated water by cooked rice. Environ. Sci. Technol. 2005, 39, 5241-5246. [CrossRef] [PubMed]

29. Kumawat, M.K.; Thakur, M.; Gurung, R.B.; Srivastava, R. Graphene Quantum Dots for Cell Proliferation, Nucleus Imaging, and Photoluminescent Sensing Applications. Sci. Rep. 2017, 7, 15858. [CrossRef] [PubMed]

30. Jin, K.; Gao, H.; Lai, L.; Pang, Y.; Zheng, S.; Niu, Y.; Li, X. Preparation of highly fluorescent sulfur doped graphene quantum dots for live cell imaging. J. Lumin. 2018, 197, 147-152. [CrossRef]

31. Kim, H.N.; Ren, W.X.; Kim, J.S.; Yoon, J. Fluorescent and colorimetric sensors for detection of lead, cadmium, and mercury ions. Chem. Soc. Rev. 2012, 41, 3210-3244. [CrossRef] [PubMed]

32. Bradley, S.J.; Kroon, R.; Laufersky, G.; Röding, M.; Goreham, R.V.; Gschneidtner, T.; Schroeder, K.; Moth-Poulsen, K.; Andersson, M.; Nann, T. Heterogeneity in the fluorescence of graphene and graphene oxide quantum dots. Microchim. Acta 2017, 184, 871-878. [CrossRef]

33. Ciotta, E.; Paoloni, S.; Richetta, M.; Prosposito, P.; Tagliatesta, P.; Lorecchio, C.; Venditti, I.; Fratoddi, I.; Casciardi, S.; Pizzoferrato, R. Sensitivity to Heavy-Metal Ions of Unfolded Fullerene Quantum Dots. Sensors 2017, 17, 2614. [CrossRef] [PubMed]

34. Chua, C.K.; Sofer, Z.; Šimek, P.; Jankovský, O.; Klímová, K.; Bakardjieva, S.; Kučková, Š.H.; Pumera, M. Synthesis of strongly fluorescent graphene quantum dots by cage-opening buckminsterfullerene. ACS Nano 2015, 9, 2548-2555. [CrossRef] [PubMed]

35. Hall, G.E.M.; Pelchat, J.C.; Gauthier, G. Stability of inorganic arsenic(III) and arsenic(V) in water samples. J. Anal. At. Spectrom. 1999, 14, 205-213. [CrossRef]

36. Hummers, W.S.; Offeman, R.E. Preparation of Graphitic Oxide. J. Am. Chem. Soc. 1958, 80, 1339. [CrossRef]

37. Kaciulis, S.; Mezzi, A.; Calvani, P.; Trucchi, D.M. Electron spectroscopy of the main allotropes of carbon. Surf. Interface Anal. 2014, 46, 966-969. [CrossRef]

38. Pizzoferrato, R.; Ziller, T.; Micozzi, A.; Ricci, A.; Sterzo, C.L.; Ustione, A.; Oliva, C.; Cricenti, A. Suppression of the excimer photoluminescence in a poly(arylene-ethynylene) co-polymer. Chem. Phys. Lett. 2005, 414, 234-238. [CrossRef]

39. Kosynkin, D.V.; Higginbotham, A.L.; Sinitskii, A.; Lomeda, J.R.; Dimiev, A.; Price, B.K.; Tour, J.M. Longitudinal unzipping of carbon nanotubes to form graphene nanoribbons. Nature 2009, 458, 872-876. [CrossRef] [PubMed]

40. Schniepp, H.C.; Li, J.L.; McAllister, M.J.; Sai, H.; Herrera-Alonson, M.; Adamson, D.H.; Prud'homme, R.K.; Car, R.; Seville, D.A.; Aksay, I.A. Functionalized single graphene sheets derived from splitting graphite oxide. J. Phys. Chem. B 2006, 110, 8535-8539. [CrossRef] [PubMed]

41. Pedrazzetti, L.; Nobili, L.; Magagnin, L.; Bernasconi, R.; Lucotti, A.; Soltani, P.; Mezzi, A.; Kaciulis, S. Growth and characterization of ultrathin carbon films on electrodeposited $\mathrm{Cu}$ and Ni. Surf. Interface Anal. 2017, 49, 1088-1094. [CrossRef]

42. Huang, J.J.; Rong, M.Z.; Zhang, M.Q. Preparation of graphene oxide and polymer-like quantum dots and their one- and two-photon induced fluorescence properties. Phys. Chem. Chem. Phys. 2016, 18, 4800-4806. [CrossRef] [PubMed]

43. Yun, L.; Kyusik, Z. Graphene oxide-modified ZnO particles: Synthesis, characterization, and antibacterial properties. Int. J. Nanomed. 2015, 10, 79-92. 
44. Kochmann, S.; Hirsch, T.; Wolfbeis, O.S. The pH dependence of the total fluorescence of graphite oxide. J. Fluoresc. 2012, 22, 849-855. [CrossRef] [PubMed]

45. Chien, C.T.; Li, S.S.; Lai, W.J.; Yeh, Y.C.; Chen, H.A.; Chen, I.S.; Chen, L.C.; Chen, K.H.; Nemoto, T.; Isoda, S.; et al. Tunable photoluminescence from graphene oxide. Angew. Chem. Int. Ed. 2012, 51, 6662-6666. [CrossRef] [PubMed]

46. Gong, Y.; Li, D.; Fu, Q.; Pan, C. Influence of graphene microstructures on electrochemical performance for supercapacitors. Prog. Nat. Sci. Mater. Int. 2015, 25, 379-385. [CrossRef]

47. Kellici, S.; Acord, J.; Ball, J.; Reehal, H.S.; Morgan, D.; Saha, B. A single rapid route for the synthesis of reduced graphene oxide with antibacterial activities. RSC Adv. 2014, 4, 14858. [CrossRef]

48. Chithiraikumar, S.; Balakrishnan, C.; Neelakantan, M.A. Tuning ligand vicinity towards development of "turn-on" fluorescence for cadmium(II) ions under physiological $\mathrm{pH}$ and bio-imaging. Sens. Actuators $B$ Chem. 2017, 249, 235-245. [CrossRef]

49. Afaneh, A.T.; Schreckenbach, G. Fluorescence Enhancement/Quenching Based on Metal Orbital Control: Computational Studies of a 6-Thienyllumazine-Based Mercury Sensor. J. Phys. Chem. A 2015, 119, 8106-8116. [CrossRef] [PubMed]

50. Xu, H.; Miao, R.; Fang, Z.; Zhong, X. Quantum dot-based turn-on fluorescent probe for detection of zinc and cadmium ions in aqueous media. Anal. Chim. Acta 2011, 687, 82-88. [CrossRef] [PubMed]

51. Kim, S.; Shin, D.H.; Kim, C.O.; Kang, S.S.; Kim, J.M.; Choi, S.H.; Jin, L.H.; Cho, Y.H.; Hwang, S.W.; Sone, C. Size-dependent radiative decay processes in graphene quantum dots. Appl. Phys. Lett. 2012, 101, 10-14. [CrossRef]

52. Li, Q.; Chen, B.; Xing, B. Aggregation Kinetics and Self-Assembly Mechanisms of Graphene Quantum Dots in Aqueous Solutions: Cooperative Effects of $\mathrm{pH}$ and Electrolytes. Environ. Sci. Technol. 2017. [CrossRef] [PubMed]

53. Wu, L.; Liu, L.; Gao, B.; Munoz-Carpena, R.; Zhang, M.; Chen, H.; Zhou, Z.; Wang, H. Aggregation kinetics of graphene oxides in aqueous solutions: Experiments, mechanisms, and modeling. Langmuir 2013, 29, 15174-15181. [CrossRef] [PubMed]

54. Yang, S.T.; Chang, Y.; Wang, H.; Liu, G.; Chen, S.; Wang, Y.; Liu, Y.; Cao, A. Folding/aggregation of graphene oxide and its application in $\mathrm{Cu}^{2+}$ removal. J. Colloid Interface Sci. 2010, 351, 122-127. [CrossRef] [PubMed]

55. Park, S.; Lee, K.; Bozoklu, G.; Cai, W.; Nguyen, K.S.T.; Ruoff, R.S. Graphene Oxide Papers Modified by DivalentIons-Enhancing Mechanical Properties via Chemical Cross-Linking. ACS Nano 2008, 2, 572-578. [CrossRef] [PubMed]

56. Barone, P.W.; Baik, S.; Heller, D.A.; Strano, M.S. Near-infrared optical sensors based on single-walled carbon nanotubes. Nat. Mater. 2005, 4, 86-92. [CrossRef] [PubMed]

57. Yang, K.; Chen, B.; Zhu, X.; Xing, B. Aggregation, Adsorption, and Morphological Transformation of Graphene Oxide in Aqueous Solutions Containing Different Metal Cations. Environ. Sci. Technol. 2016, 50, 11066-11075. [CrossRef] [PubMed]

58. Wang, J.; Chen, B. Adsorption and coadsorption of organic pollutants and a heavy metal by graphene oxide and reduced graphene materials. Chem. Eng. J. 2015, 281, 379-388. [CrossRef]

59. Sitko, R.; Turek, E.; Zawisza, B.; Malicka, E.; Talik, E.; Heimann, J.; Gagor, A.; Feist, B.; Wrzalik, R. Adsorption of divalent metal ions from aqueous solutions using graphene oxide. Dalton Trans. 2013, 42, 5682. [CrossRef] [PubMed]

60. Gopalakrishnan, A.; Krishnan, R.; Thangavel, S.; Venugopal, G.; Kim, S.J. Removal of heavy metal ions from pharma-effluents using graphene-oxide nanosorbents and study of their adsorption kinetics. J. Ind. Eng. Chem. 2015, 30, 14-19. [CrossRef]

61. Szabò, T.; Tombacz, E.; Illès, E.; Dèkàny, I. Enhanced acidity and pH-dependent surface charge characterization of successively oxidized graphite oxides. Carbon 2006, 44, 537-545. [CrossRef]

62. Gu, D.; Fein, J.B. Adsorption of metals onto graphene oxide: Surface complexation modeling and linear free energy relationships. Colloids Surf. A Physicochem. Eng. Asp. 2015, 481, 319-327. [CrossRef]

63. Yang, X.; Xia, L.; Song, S. Arsenic Adsorption from Water Using Graphene-Based Materials as Adsorbents: A Critical Review. Surf. Rev. Lett. 2017, 24, 1730001. [CrossRef]

64. Shtepliuk, I.; Khranovskyy, V.; Yakimova, R. Insights into the origin of the excited transitions in graphene quantum dots interacting with heavy metals in different media. Phys. Chem. Chem. Phys. 2017, 19, 30445-30463. [CrossRef] [PubMed] 
65. McNaught, A.W.; Alan, D. Compendium of Chemical Terminology, 2nd ed.; Wiley-Blackwell: Oxford, UK, 2014.

66. Xue, L.; Liu, C.; Jiang, H. Highly Sensitive and Selective Fluorescent Sensor for Distinguishing Cadmium from Zinc Ions in Aqueous Media. Org. Lett. 2009, 11, 1655-1658. [CrossRef] [PubMed]

67. Goswami, P.; Das, D.K. A new highly sensitive and selective fluorescent cadmium sensor. J. Fluoresc. 2012, 22, 391-395. [CrossRef] [PubMed] 